\title{
DISTRIBUIÇÃO DE GLEICHENIA SP. AO LONGO DA TRILHA ABRAÃO-DOIS RIOS, ILHA GRANDE - RJ: CAUSAS E IMPACTOS
}

\author{
Victor Hugo Arona do Monte ${ }^{(\mathrm{a})}$, Manuela Bittencourt V. dos Santos $^{(\mathrm{b})}$, Achilles d'AvilaChirol $^{(\mathrm{c})}$ \\ (a) Aluno de graduação do curso de Geografia da Universidade Estadual do Rio de Janeiro, vhadm21@ gmail.com \\ (b) Aluna de graduação do curso de Geografia da Universidade Estadual do Rio de Janeiro, bittencourt- \\ manuela@hotmail.com \\ (b) Professor Adjunto do Departamento de Geografia Física da Universidade Estadual do Rio de Janeiro, \\ achilleschirol@gmail.com
}

\section{EIXO: BIOGEOGRAFIA, MANEJO DE ÁREAS NATURAIS E PROTEGIDAS: CONSERVAÇÃO DA BIODIVERSIDADE}

\begin{abstract}
Resumo:
Ao longo da trilha de Abraão-Dois Rios observam-se diversos pontos onde há a dominância de Gleichenia $s p$. Estas podem funcionar como facilitadoras ou inibidoras da sucessão ecológica, e por isso é fundamental entender o seu papel ecológico na sucessão. Dentro disto o presente trabalho pretende observar os elementos que condicionam o estabelecimento das Gleichenias os seus impactos para o ambiente, fazendo análises microclimáticas e de penetrabilidade do solo.
\end{abstract}

Palavras chave:Biogeografia;Ecologia de Gleichenia; Ilha Grande;Conservação;Manejo de áreas conservadas.

\section{Introdução}

A trilha Abraão-Dois Rios liga o principal centro de entrada da Ilha Grande (Abraão) com a comunidade de Dois Rios, onde ficava a antiga colonia penal e hoje se encontra uma comunidade com aproximadamente 100 habitantes. É uma trilha larga e com aproximadamente $11 \mathrm{~km}$ de extensão, onde chama atenção na paisagem os diversos pontos de concentração de Gleichenia sp., uma pteridofita muito comum na Mata Atlântica, que costuma dominar em áreas onde houve algum tipo de perturbação que permite maior entrada de luz e alterações de solo.Heinrich (1986) observou que espécies de pteridófitas dos gêneros Pteridium (Dennstaedtiaceae), Gleichenia e Gleichenella (Gleicheniaceae) são favorecidas em áreas onde os solos estão empobrecidos e degradados, podendo inclusive um elemento importante no processo de sucessão, servindo como facilitadoras na sucessão ecológica. Este é um padrão que já foi visto em estudos anteriores, como Castro Jr. et al (1997), Chirol (2009) eMontezuma (2005), em áreas de Mata Atlântica, destacando o seu importante papel na colonização na colonização de áreas expostas por movimentos de massa e Cusatis (2001), queobservou que Melinisminutiflora (capim-gordura) e duas espécies da família Gleicheniaceae são as maisadaptadas a solos de extrema pobreza no Estado de Minas Gerais. 
A questão é que se as Gleichenias dominam em uma área muito extensa, estas podem impedir o estabelecimento de outras espécies, diminuindo a biodiversidade e vulnerabilizando a área. Desta forma é importantíssimo entender os fatores que condicionam a sua distribuição e os impactos que estas causam, tanto do ponto de vista físico como biológico, e assim desenvolver conhecimentos que possam auxiliar na gestão da Ilha Grande.

O presente trabalho está inserido dentro das pesquisas do Núcleo de Ensino e Pesquisa em Planejamento Territorial (NEPPT/UERJ), desenvolvidos no CEADS/UERJ da Ilha Grande, com ênfase nos impactos da atividade turística em suas múltiplas variáveis, analisando a trilha de Dois Rios e suas características ambientais como um microcosmo da própria Ilha, fazendo análises microclimáticas, testes de penetrabilidade de solo e caminhamento expeditivos. As análises de mciroclima e penetrabilidade ainda estão em andamento, e os resultados serão apresentados no Simpósio.

\section{2. Área de Estudo}

A Ilha Grande, distrito do município de Angra dos Reis, está localizada na Baía da Ilha Grande, litoral sul do estado do Rio de Janeiro, Brasil (Figura 1) e constitui-se no recorte espacial de análise do trabalho. A baía possui uma área de 65.258 ha e cerca de $350 \mathrm{~km}$ de perímetro na linha d'água, separados em dois corpos d'água construídos pela aproximação existente entre continente e Ilha Grande, formando o Canal Central (CREED et al., 2007, p. 46). Praticamente toda a área da ilha é contemplada por unidades de conservação, entre as quais podem ser citadas o Parque Estadual da Ilha Grande (PEIG), a reserva biológica da praia do Sul, e a área de proteção ambiental do Tamoios e a Reserva Marinha do Aventureiro. Em resposta a esses elementos do meio físico, a vegetação (CALLADO et al, 2009) é composta por floresta ombrófila densa (montana, sub-montana e de terras baixas) que ocupa a maior parte da superfície da ilha, restinga, mata alagadiça e manguezais. A maior parte desta vegetação é secundária, consequência do uso (OLIVEIRA, 1999), com a presença de algumas espécies exóticas introduzidas.

A trilha estudada liga Abraão, que é o principal centro da Ilha, à comunidade de Dois Rios, onde ficava a extinta colônia penal. A trilha ainda é a principal forma de comunicação entre as duas localidades, e apresenta diversos pontos de degradação, como movimentos de massa, vegetação pioneira e sulcos erosivos, resultado do seu histórico de uso. O que se encontra então é uma floresta secundária com a presença de diversas espécies exóticas em uma área que está inserida no PEIG. 

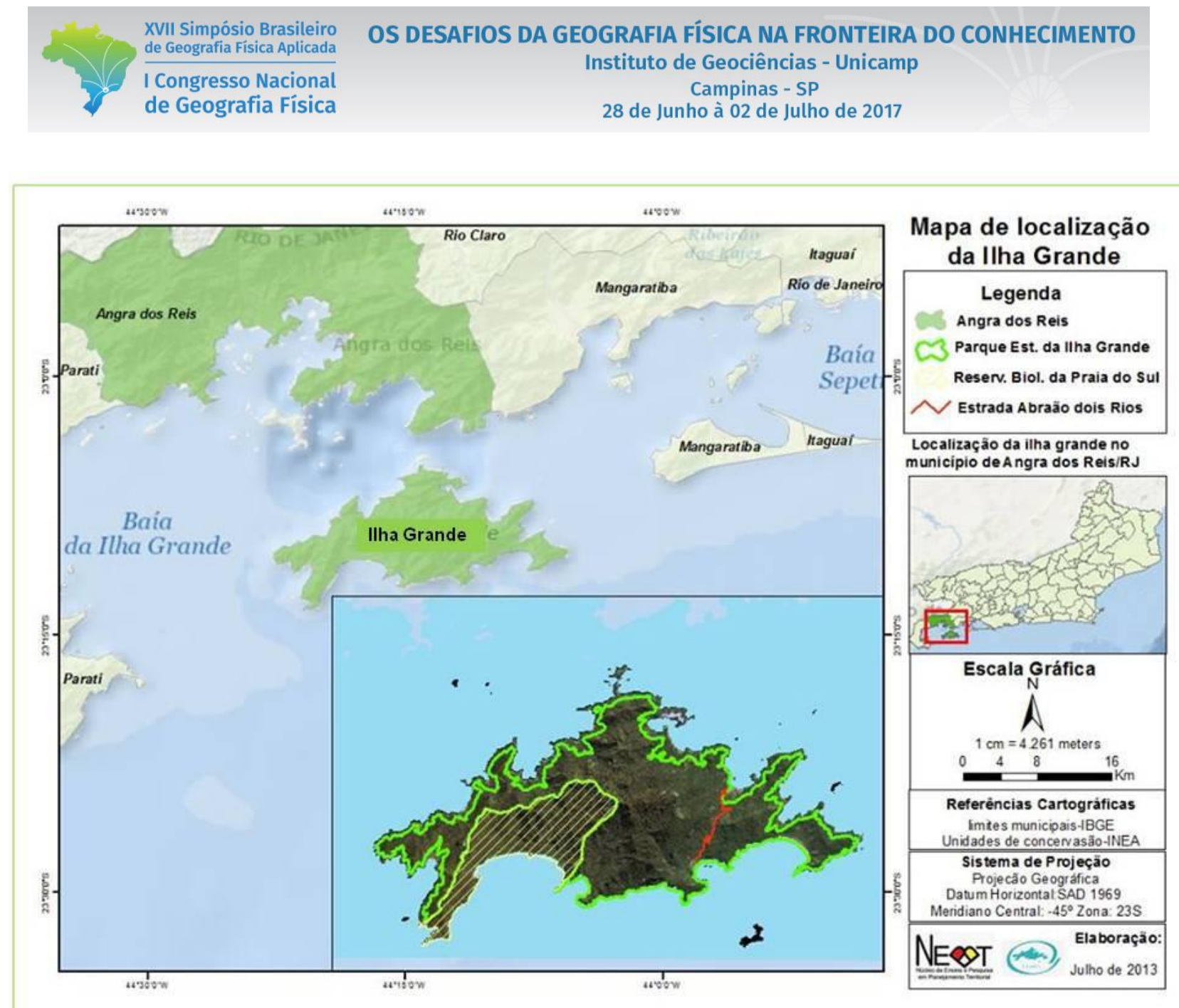

Figura 1 - Mapa de localização da Ilha Grande. Fonte: NEPPET/UERJ

\section{Metodologia}

Para o presente trabalho já foram realizados trabalhos de campo para identificação das principais áreas de domínio das Gleichenia, e a partir disto serão feitas as seguintes análises tanto nas áreas dominadas pelas pteridófitas como uma área controle de floresta:

- $\quad$ Análises de penetrabilidade de solo, com penetrômetro de impacto

- Análise microclimática ao nível do solo e a 1 metro de altura, para comparar as diferenças em função da ação da cobertura vegetal. Serão medidas a temperatura, umidade relativa do ar, luminosidade e velocidade do vento com um Anemômetro Termohigro Luxímetro Digital LM-8000 Lutron. 


\section{Conclusões}

Ao longo da trilha podem ser observados diversos pontos de dominância das Gleichenia, como por exemplo na figura 2. Infere-se que no contato com a mata deve haver um forte efeito de borda, por conta da entrada de luz e vento pelas diferentes características microclimáticas entre florestas e pteridófitas. A grande questão é entender a dimensão destas diferenças e o balanço entre o papel de facilitadora ou inibidora das Gleichenia sp. Negishiet al (2006), estudando o papel de uma espécie de Gleichenia na recuperação de uma área de trilha, observou que A cobertura gerada manteve a temperatura média diária comparável à da floresta $\left(<28{ }^{\circ} \mathrm{C}\right)$, enquanto a superfície aberta da trilha atingiu $40{ }^{\circ} \mathrm{C}$. Os autores sugeriram que a espécie tem potencialmente um papel ecológico importante na recuperação de trilhas, reduzindo as perdas geradas pela erosão e acumulando sedimentos onde sementes podem germinar, enriquecendo o solo com nutrição mineral e moderando as temperaturas.

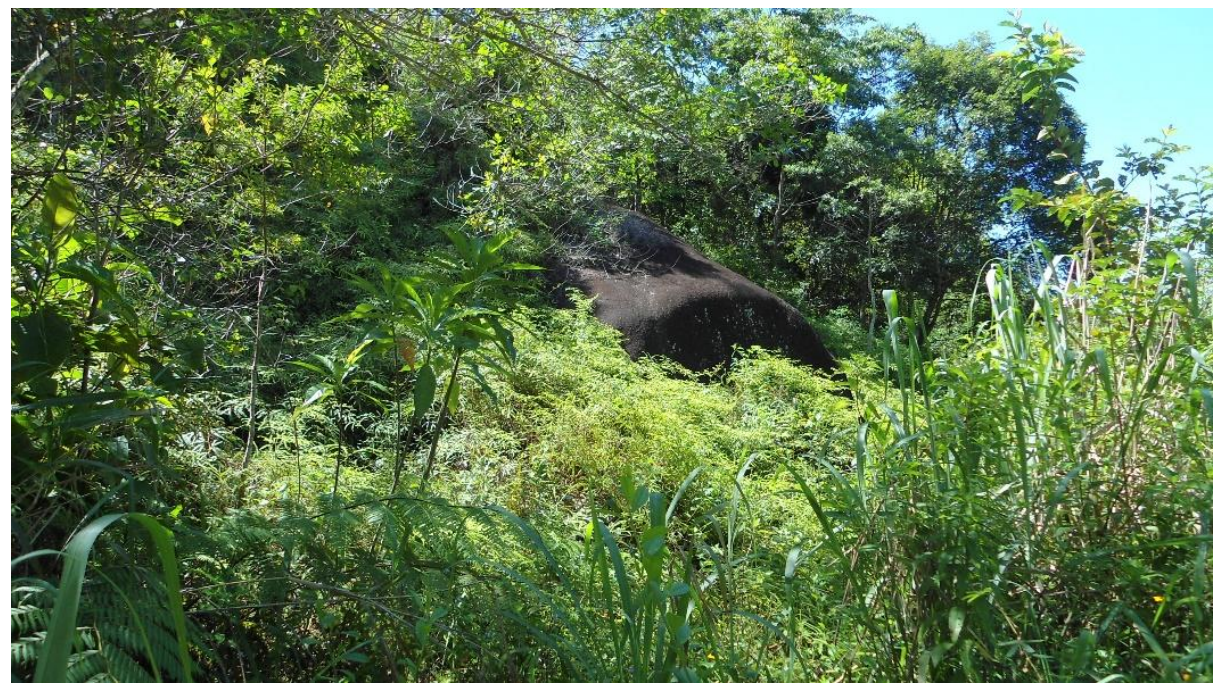

Figura 2: Área de dominância de Gleichenia na trilha Abraão-Dois Rios.

\section{Considerações Finais}

É fundamental estudo do padrão de ocupação da Gleichenia, uma vez que o seu papel pode ser tanto de facilitadora como inibidora do processo sucessional. O presente trabalho procura contribuir no entendimento do papel ecológico destas pteridófitas, entendendo os seus impactos para o ambiente e os fatores controle da sua distribuição, e assim pensar em formas de manejo para a conservação de áreas de Mata Atlântica. Como já foi explicado na introdução, os dados de penetrabilidade do solo e de microclima serão apresentados no congresso. 


\section{Agradecimentos}

Centro de Estudo Ambientais e Desenvolvimento Sustentável (CEADS/UERJ)e Fundação de Amparo à Pesquisa do Estado do Rio de Janeiro (FAPERJ).

\section{Bibliografia}

CASTRO JR, E., ROCHA LEÃO, O M., TURETTA, A P.D.; CRUZ, E.S.; BALESDANT, F.C.; SENRA, L.C.; COELHO NETTO, A.L.; Estudo da colonização espontânea e resultantes hidro-erosivas em cicatrizes de movimento de massa: Cicatriz da Vista do Almirante - PARNA - Tijuca, RJ; Anais do III Simpósio Nacional de Recuperação de áreas degradadas, UFV, pág. 259-269. 1996.

CHIROL A. A.,Relações solo-fauna durante sucessão florestal em cictrizes de deslizamento; Dissertação de Mestrado, P.P.G. em Geografia/UFRJ, 2009.

CREED, J.C; PIRES, Débora O; FIGUEIREDO, Marcia A. de. Biodiversidade Marinha da Baía da Ilha Grande. Brasília: MMA/SBF, 2007.

CUSATIS, A. C. Diagnósticos de Taludes Rodoviários Revegetados Naturalmente na Região de Viçosa, MG. Dissertação de Magister Scientiae. UFV. Viçosa, MG. 2001.

MONTEZUMA, R. C. M. Produção e reabilitação funcional do piso florestal em clareira de deslizamento - PARNA Tijuca, Rio de Janeiro; Tese de Doutorado, PPG em Geografia/UFRJ. 2005.

HEINRICH, W. Vegetação e zonas climáticas: tratado de ecologia global. Ed.Pedagógica e Universitária, São Paulo-SP.1986.

NEGISHI, J.N. SIDLE, R.C., NOGUCHI S., NIK, A.B. \& STANFORTH, R..Ecological roles of roadside fern (Dicranopteriscurranii) on logging road recovery in Peninsular Malaysia: Preliminary results. Forest Ecologyand Management vol224: pág. 176-186. 2006.

OLIVEIRA, R.R.O rastro do homem na floresta: Sustentabilidade e funcionalidade da Mata Atlântica sob manejo caiçara; P.P.G. em Geografia /UFRJ, Tese de Doutorado. 1999. 